\title{
Impact of single visit of Lipotriches collaris Vachal 1903 (Hymenoptera: Halictidae) on Phaseolus vulgaris (Fabaceae) flowers at Maroua (Cameroon)
}

\author{
Chantal Douka $^{1 *}$, Joseph Lebel Tamesse ${ }^{1}$, Fernand-Nestor Fohouo tchuenguem ${ }^{2}$ \\ ${ }^{1}$ Laboratory of Zoology, Higher Teacher Training College University of Yaoundé I, Yaoundé, Cameroon. \\ ${ }^{2}$ Laboratory of Applied Zoology, Faculty of Science, University of Ngaoundéré, Ngaoundéré, Cameroon.
}

\section{ARTICLE INFO}

Article history:

Received on: 13/05/2016

Accepted on: 17/12/2016

Available online: 20/03/2017

\section{Key words:}

Lipotriches collaris, Phaseolus vulgaris, pollen, nectar, pollination.

\begin{abstract}
To evaluate the impact of single visit of Lipotriches collaris on pod and seed yields of Phaseolus vulgaris (Red and Small Seeds), its foraging and pollinating activities were studied in Maroua, during 2010, 2011 and 2013 cropping seasons. Treatments included bagged flowers to avoid all visits and bagged flowers limited on a single visit of $L$. collaris. Observations were made on 147, 139 and 138 flowers in 2010, 2011 and 2013 respectively. The foraging behavior on flowers and its pollination efficiency (fruiting rate, number of seeds/pod and percentage of normal seeds) were recorded. Lipotriches collaris foraged pollen and nectar. The foraging activities of $L$. collaris increase the fruiting rate by $39.49 \%$ and the number of seeds/pod by 14.65 $\%$. Conservation of $L$. collaris nest close to $P$. vulgaris crop fields should be recommended to improve pod and seed production in the region.
\end{abstract}

\section{INTRODUCTION}

Phaseolus vulgaris is a plant that originated from South and Central America [1]. Bean plants are bushy or upright (40 to $60 \mathrm{~cm}$ ); Climbing stems are slightly branched; the leaves are stalked; alternate and compound trifoliate; green or purple [2]. Flowering starts 28-35 days after sowing; the flower is pink, but can vary from white to purple depending on the different varieties [3] and produces nectar/pollen which attract insects [4-5]. Phaseolus vulgaris flowers were reported to produce fewer seeds per pod in the absence of efficient pollinators in the United States of America [2]. In Dang (Ngaoundere-Cameroon) the activities of Xylocopa olivacea on flowers of $P$. vulgaris increase the fruiting rate by $63.30 \%$, the number of seeds/pod by $18.98 \%$ and the normal seeds by $26.96 \%$ [4]. Recent research conducted in Maroua in 2013 by Douka and Tchuenguem [5] has revealed that Apis mellifera adansonii visiting $P$. vulgaris (Red and Small Seeds) flowers this insect behavior for nectar and pollen and increase the fruiting rate by $55.32 \%$, the number of seeds/pod by $19.10 \%$ and the normal seeds by $7.71 \%$. Cross-pollination by insects is generally observed [4-5-6-7] and this plant is autogam/allogam [2-4-5]. In Cameroon, $P$. vulgaris can be consumed as vegetable raw or cooked, or transformed into flour,

\footnotetext{
* Corresponding Author

E-mail: chantaldouka@yahoo.fr
}

while the stems and leaves are used to feed livestock [3]; the production of $P$. vulgaris is 353,729 tons, but the projections of production is more than 500,000 tons [8]. Therefore, it is important to investigate on the possibilities of increasing the production of this plant in Cameroon. The main objective of this research was to gather data on the relationships between $P$. vulgaris and L. collaris in Maroua, for optimal management of pollination services in Cameroon. Specific objectives were the registration of the activities and this efficiency pollination on this plant.

\section{MATERIALS AND METHODS}

\subsection{Study site, experimental plot and biological material}

The studies were conducted from June-September in 2010, 2011 and 2013 respectively in the locality of Maroua (Latitude $10^{\circ}$ 62 'N, Longitude $14^{\circ} 33^{\prime} \mathrm{E}$ and altitude $400 \mathrm{~m}$ ), Far North Region of Cameroon. This Region belongs to the ecological zone with three phytogeographical areas: Sahel-Sudanian, Sahelian and Sudanian altitude, which is periodically flooded with unimodal rainfall [9]. It has a Sahel-Sudanian climate type, characterized by two annual seasons: a long dry season (November to May) and a short rainy season (June to October); August is the wettest month of the year; annual rainfall varies from 400 to $1100 \mathrm{~mm}$; the annual average temperature varies between $29{ }^{\circ} \mathrm{C}$ and $38{ }^{\circ} \mathrm{C}$ and a daily temperature range between $6{ }^{\circ} \mathrm{C}$ and $7{ }^{\circ} \mathrm{C}[10]$. 
The experimental plot is an area of $156 \mathrm{~m}^{2}$. The insect in this study was Lipotriches collaris Vachal 1903 (Hymenoptera: Halictidae). The plant was Phaseolus vulgaris (Red and Small Seeds). The seeds of this plant were provided by IRAD (Institut de Recherche Agricole pour le Développement) of Maroua.

\subsection{Sowing and weeding}

On June 12, 2010, June 15, 2011 and July 13, 2013, the experimental plot was cleaned and divided into 24 subplots, each measuring $1 \mathrm{~m} \times 1.5 \mathrm{~m}$. Two seeds were sown in 2 lines per subplot, each of which had 5 holes per line. Holes were separated $30 \mathrm{~cm}$ from each other, while lines were $80 \mathrm{~cm}$ apart. Weeding was performed manually as necessary to maintain plots in a weedfree state.

\subsection{Foraging activities and Pollination efficiency of Lipotriches collaris on Phaseolus vulgaris}

From July 8 to $2^{\text {nd }}$ August 2010, July 16 to 7 August 2011 and August 15 to 5 September 2013, 147, 139 and 138 flowers were isolated at bud stage respectively and for each year two treatments were made. Treatment 1 was made by bagged flowers with gauze bag to avoid all visits (figure 1) and treatment 2 was constituted by bagged flowers limited on a single visit of $L$. collaris.

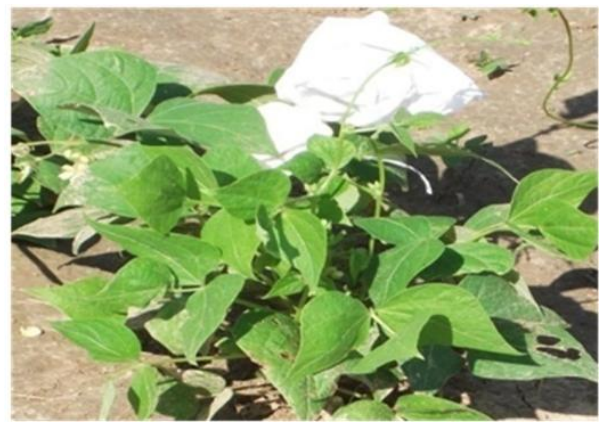

Fig. 1: Plant of Phaseolus vulgaris showing a flower isolated from insects..

On treatment 2 between 6 and $9 \mathrm{~h}$ am of each observation date and each year; the gauze bag was delicately removed from each opened flower and this flower observed for up to $10 \mathrm{~min}$. The flowers visited by $L$. collaris were labeled after this manipulation (Figure 2).

For foraging activities observations were conducted at the same date and the same time (6- $9 \mathrm{~h}$ am).

The floral rewards (nectar or pollen) harvested by $L$. collaris during each floral visit were registered based on its foraging behavior. Nectar foragers were expected to extend their proboscis to the base of the corolla and the stigma, while pollen gatherers were expected to scratch the anthers with their mandibles or legs [11]. In the morning of each day, the number of opened flowers on $P$. vulgaris plant was counted.

For the abundances of $L$. collaris, large numbers of the insect were found to be simultaneously active per flower and per 1000 flowers, $1000\left(A_{1000}\right)$ were recorded. The first parameter was recorded as a result of direct counts. For $A_{1000}, L$. collaris were counted on a known number of open flowers. $A_{1000}$ was then calculated using the formula: $A_{1000}=[(A x / F x) 1000]$, where $F x$ and $A x$ are the number of opened flowers and the number of $L$. collaris effectively counted on these flowers at time $x$ respectively [12-13].

The duration of individual flower visits was recorded (using a stopwatch).

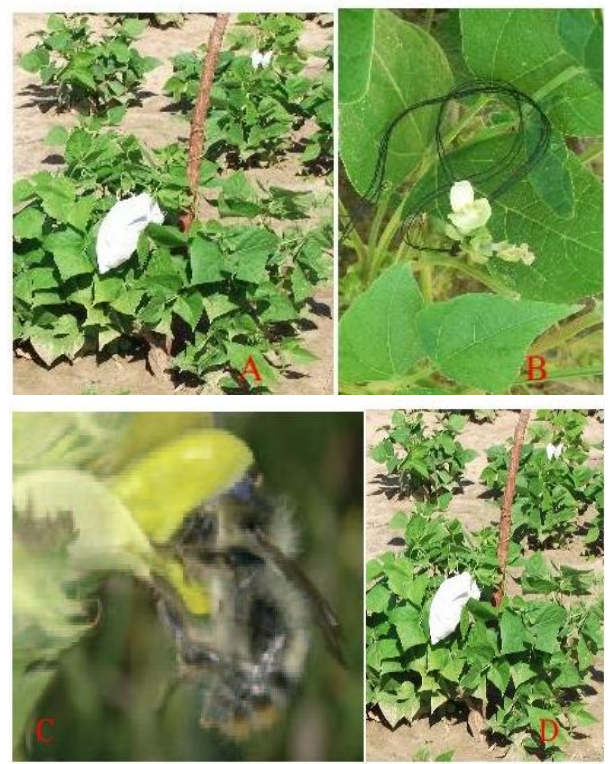

Fig. 2: Steps of manipulation on Phaseolus vulgaris flowers from treatment 2. (A) Plant showing bagged flowers of P. vulgaris, (B) Opened flowers after delicate removal from the gauze bag, $(C)$ a single visit of $L$. collaris on the opened flower, (D) After a single visit of L. collaris the flower was labeled.

Two week after the end of observation (16 August 2010, 21 August 2011 and 19 September 2013) for each treatment the number of pod and the number of seeds per pod were counted then the quality of seed was also appreciated. The contribution $(F r l c)$ of $L$. collaris to fruiting was calculated by the formula: $F r l c=$ $\{[(F r 2-F r 1) / F r 2] \times 100\}$. Where $F r 1$ and $F r 2$ are the fruiting rates in treatment 1 (protected flowers) and in treatment 2 (protected flowers and visited exclusively by $L$. collaris). For the fruiting rates $((F r)$ was then calculated as described by Tchuenguem et al. [12]: $F r=F 2 / F 1$. Where $F 2$ is the number of pods formed and $F 1$ the number of viable flowers initially set). The mean number of seeds per pod and the percentage of normal seeds were then calculated for each treatment.

\subsection{Data analysis}

Data were analyzed using descriptive statistics with Microsoft Excel 2007, Student's $(t)$ test for the comparison of the average number of seeds per boll between treatments 1 (bagged flowers to avoid all visits) and treatment 2 (bagged flowers limited on a single visit of $L$. collaris). Correlation coefficient $(r)$ was used to study of the association between the variables of abundance of L. collaris and opened flowers. Chi - Square $\left(\chi^{2}\right)$ test was used for the comparison of fruiting rates and the percentage of normal seeds between treatments 1 and 2. Comparison of the means of 
duration of visits and the abundance of $L$. collaris of 2010, 2011 and 2013 was done using ANOVA $(F)$.

\section{RESULTS}

\subsection{Activity of Lipotriches collaris on Phaseolus vulgaris flowers}

\subsubsection{Floral rewards harvested}

From our field observations, L. collaris were found to collect pollen and nectar on $P$. vulgaris flowers. Pollen collection was regular and intensive whereas nectar collection was regular but less intensive. In 62, 52 and 34 visits counted on flowers, respectively in 2010, 2011 and 2013, 45 (72.58\%), $37(71.15 \%)$ and $16(47.05 \%)$ were for pollen collection and $17(27.41 \%), 15$ $(28.84 \%)$ and $18(52.94 \%)$ for nectar collection, respectively in 2010, 2011 and 2013 (Table 1).

Table 1: Products harvested by Lipotriches collaris on flowers of Phaseolus vulgaris in 2010, 2011 and 2011 in Maroua.

\begin{tabular}{cccccc}
\hline & \multicolumn{3}{c}{$\begin{array}{c}\text { Visits for pollen } \\
\text { harvest }\end{array}$} & \multicolumn{2}{c}{$\begin{array}{c}\text { Visits for nectar } \\
\text { harvest }\end{array}$} \\
\hline Year & $\begin{array}{c}\text { Number } \\
\text { of visits }\end{array}$ & Number & $\%$ & Number & $\%$ \\
\hline 2010 & 62 & 45 & 72.58 & 17 & 27.41 \\
2011 & 52 & 37 & 71.15 & 15 & 28.84 \\
2013 & 34 & 16 & 47.05 & 18 & 52.94 \\
Total & $\mathbf{1 4 8}$ & $\mathbf{9 8}$ & $\mathbf{6 6 . 2 2}$ & $\mathbf{5 0}$ & $\mathbf{3 3 . 7 8}$ \\
\hline
\end{tabular}

Comparison of the percentage of harvest visits for the three years of investigation: Nectar/ Pollen: $\chi^{2}=7.27(d d l=2 ; P<0.05)$.

\subsubsection{Relationship between visits and flowering stages}

Positive and significant correlation was found between the number of $P$. vulgaris opened flowers and the number of $L$. collaris visits in $2010(r=0.68 ; d f=19 ; p<0.001)$, in $2011(r=$ $0.66 ; d f=19 ; p<0.001)$ and in $2013(r=0.62 ; d f=19 ; p<0.01)$ (Figure 3).

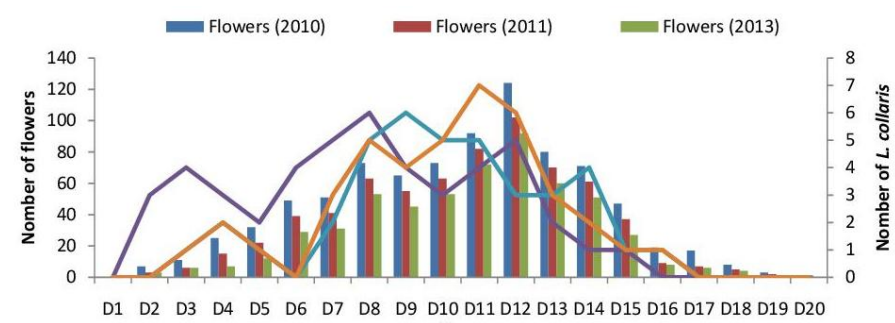
Days

Fig. 3: Variation of number of flowers and number of Lipotriches collaris on flowers of Phaseolus vulgaris in 2010, 2011 and 2013 in Maroua.

\subsubsection{Abundance of Lipotriches collaris}

In 2010, the highest average number of $L$. collaris simultaneously active was one per flower $(n=30, s=0)$ and 132.76 per 1000 flowers $(n=37, s=121.55, \max =400)$. In 2011, the corresponding figures were 1 per flower $(n=30, s=0)$ and 147.92 per 1000 flowers $(n=45, s=100.55$, $\max =500)$. In 2013, the results were 1 per flower $(n=30, s=0)$ and 119.23 per 1000 flowers $(n=42, s=98.14, \max =456)$. The difference between the average number of $L$. collaris per 1000 flowers in 2010, 2011 and 2013 is significant $(F=2.71[d f=122, P<0.05])$.

\subsubsection{Duration of visits per flower}

The average duration of a visit of $L$. collaris per flower of $P$. vulgaris varied significantly depending on the substance taken. In 2010, the average duration of a visit for pollen collection was $1.84 \mathrm{sec}(n=45, s=0.57, \max =8)$; for the collection of nectar, it was $1.45 \mathrm{sec}(n=71, s=0.51, \max =5)$. In 2011, the corresponding results were $1.94 \sec (n=37, s=0.78, \max =7)$ and $1.77 \mathrm{sec}(n=15, s=0.81, \max =5)$ for pollen and nectar harvest respectively. In 2013, were have found $1.58 \mathrm{sec}(n=16, s$ $=0.95, \max =9)$ for pollen and $1.32 \mathrm{sec}(n=18, s=0.47, \max =$ 6) for nectar.

The difference between the three means durations is significant for nectar harvest $(F=3.37[d f=48, P<0.05])$ and for pollen collecting $(F=4.09,[d f=96, P<0.05])$.

\subsection{Pollination efficiency of Lipotriches collaris on Phaseolus vulgaris}

During pollen and nectar harvest on $P$. vulgaris, $L$. collaris always shook flowers and are regularly in contact with the anthers and stigma, increasing cross-pollination possibility of $P$. vulgaris fruiting rate and number of seeds per pod in different treatments (Table 2).

a) The difference observed between the fruiting rate of treatment 2 and that of treatment 1 was significant in $2010\left(\chi^{2}=\right.$ $4.61[d f=1, P<0.05])$, in $2011\left(\chi^{2}=5.34[d f=1, P<0.05]\right)$ and in $2013\left(\chi^{2}=5.40[d f=1, P<0.05]\right)$. Therefore, the rate of fruit set of flowers isolated and visited exclusively by $L$. collaris (treatments 2) is higher than that of protected flowers (treatments 1). In 2010, 2011 and 2013, the percentages of fruiting rate attributed to the efficiency of pollinating of $L$. collaris were $39.55 \%, 37.77 \%$ and $41.17 \%$ respectively. For the three years of experiments, the percentage is $39.49 \%$.

b) There was a highly significant difference between the number of seeds per pod of treatments 2 and $1(t=-5.08[(d f=49$, $P<0.001])$ in the first year, the second year $(t=-11.61[(d f=58$, $P<0.001])$ and the third year $(t=-3.83[(d f=51, P<0.001])$. High mean number of seeds per pod of flowers of treatment 2 was noticed compared to flowers of treatment 1. Consequently, in 2010, 2011 and 2013, the number of seeds per pod of flowers isolated and visited exclusively by $L$. collaris (treatments 2 ) was higher than that of protected flowers (treatments 1). Percentages of the number of seeds per pod affected to the pollination efficiency of L. collaris were $14.39 \%, 19.13 \%$ and $10.45 \%$ respectively in 2010, 2011 and 2013. For the three seasons of study, this percentage was $14.65 \%$.

c) There was no significant difference between the percentage of normal seed of treatment 2 and that of treatment 1 in the first year $\left(\chi^{2}=3.19[d f=1, P>0.05]\right)$, the second year $\left(\chi^{2}=\right.$ $0.30[d f=1, P>0.05])$ and the third year $\left(\chi^{2}=0.63[d f=1, P>\right.$ 0.05]). Therefore, in 2010, 2011 and 2013, the percentage of normal seeds from flowers isolated and visited exclusively by $L$. collaris (treatment 2) was not higher than that of protected flowers (treatment 1). 
Table 2: Phaseolus vulgaris yields under pollination treatments.

\begin{tabular}{|c|c|c|c|c|c|c|c|c|c|}
\hline \multirow{2}{*}{ Treatments } & \multirow{2}{*}{ Year } & \multirow{2}{*}{ F Flowers } & \multirow{2}{*}{ Boll } & \multirow{2}{*}{ Fruiting Rate } & \multicolumn{2}{|c|}{ Seeds/Boll } & \multirow{2}{*}{$\begin{array}{l}\text { Total } \\
\text { Seeds }\end{array}$} & \multirow{2}{*}{$\begin{array}{c}\text { Normal } \\
\text { Seeds }\end{array}$} & \multirow{2}{*}{$\begin{array}{c}\% \% \\
\text { Normal Seeds }\end{array}$} \\
\hline & & & & & mean & $s d$ & & & \\
\hline $1(\mathrm{Fi})$ & 2010 & 108 & 32 & 29,62 & 3,33 & 1,39 & 99 & 84 & 84,84 \\
\hline $2(\mathrm{Fv} l)$ & & 39 & 19 & 49,00 & 3,89 & 1,09 & 152 & 140 & 92,11 \\
\hline $1(\mathrm{Fi})$ & 2011 & 108 & 41 & 37,96 & 3,93 & 1,05 & 173 & 154 & 89,01 \\
\hline $2(\mathrm{Fv} l)$ & & 31 & 19 & 61,00 & 4,86 & 0,96 & 122 & 111 & 90,98 \\
\hline $1(\mathrm{Fi})$ & 2013 & 108 & 36 & 33,33 & 3,17 & 1,18 & 126 & 109 & 86,50 \\
\hline $2(\mathrm{Fv} l)$ & & 30 & 17 & 56,66 & 3,54 & 0,88 & 54 & 49 & 90,74 \\
\hline
\end{tabular}

Fi: isolated flowers ; Fvl: isolated flowers and then visited exclusively by Lipotriches collaris.

\section{DISCUSSION}

\subsection{Activity of Lipotriches collaris on Phaseolus vulgaris flowers}

\subsubsection{Floral rewards harvested}

During each of the three flowering periods of $P$. vulgaris, L. collaris intensively and regularly harvested pollen or nectar. This could be attributed to the needs of this bee during the flowering period and it indicates that $L$. collaris can provide benefits to pollination of P. vulgaris in Maroua [14]. Similar observations were found on flowers of some Fabaceae witch A. $m$. adansonii (Hymenoptera: Apidae) workers foraging on flowers of Entada africana, Glycine max, Vigna unguiculata [15-16-17-18], Chalicodoma cincta cinta (Hymenoptera: Megachilidae) foraging on Cajanus cajan flowers [19] and Xylocopa olivacea (Hymenoptera: Apidae) workers foraging P. vulgaris flowers [4]. The weight of $L$. collaris played a positive role during pollen and nectar collection. Lipotriches collaris shook flowers, facilitating the liberation of pollen by anthers for the optimal occupation of the stigma [14].

\subsubsection{Relationship between visits and flowering stages}

Lipotriches collaris was the main floral visitor of $P$. vulgaris flowers during the observation period. Halictidae have been reported as the main floral visitor of $P$. vulgaris, $P$. coccineus and Glycine $\max$ flowers in Cameroon [4,15,20]. The significant difference between the percentage visits of $L$. collaris within the years of study could be attributed to the experimental site variation. In field conditions, the activity of bee on flowers was dependent on the site and in the same conditions this activity varied with years, the climatic factors and the availability of pollen and nectar on flowers [15-20].

\subsubsection{Abundance of Lipotriches collaris}

The abundance of $L$. collaris foragers on 1000 flowers and the positive and significant correlation between the number of $P$. vulgaris flowers (as bloom), as well as, the number of $L$. collaris visits indicated the attractiveness of $P$. vulgaris pollen and nectar. In fact, weather during bloom was demonstrated to affect the abundance and foraging of pollinator insects [21].

Similar observations were made in Maroua witch A. $\mathrm{m}$. adansonii and Macronomia vulpina on Alum cepa, Gossypium hirsutum and G. max flowers [22-24].

\subsubsection{Duration of visits per flower}

The significant difference between the duration of visits in 2010, 2011 and 2013 could be attributed to the availability of floral products or the variation of diversity of flowering insects from one year to another. During each of the three flowering periods of $P$. vulgaris, $L$. collaris intensely and regularly harvested nectar and pollen. This could be attributed to the needs of individuals at flowering period. Similar observations were made for A. m. adansonii workers foraging on Entada africana and Vigna unguiculata (Fabaceae) flowers [17-18], and for Chalicodoma cincta (Hymenoptera: Megachilidae) foraging on Cajanus cajan (Fabaceae) flowers [20].

\subsection{Pollination efficiency of Lipotriches collaris on Phaseolus vulgaris}

During the collection of nectar and pollen on each flower, L. collaris foragers regularly come into contact with the stigma. They were also able to carry pollen with their hairs, legs and mouth accessories from a flower of one plant to stigma of another flower of the same plant (geitonogamy), to the same flower (autogamy) or to that of another plant (xenogamy).

The significant contribution of $L$. collaris in pods and seed yield of $P$. vulgaris is in agreement with similar findings in Ngaoundere (Cameroon) [4], England [25] and United State of America [2] which showed that $P$. vulgaris flowers produce fewer seeds per pod in the absence of efficient pollinators.

The contribution of $L$. collaris to $P$. vulgaris production through its pollination efficiency was significantly higher than that of isolated flowers. The weight of $L$. collaris played a positive role during nectar and pollen collection. Lipotriches collaris shook flowers facilitating the liberation of pollen by anthers for the optimal occupation of the stigma. Our results confirmed those of Azo'o et al. [26] who revealed that the development of fruits from Abelmoschus esculentus (L.) Moench (Malvaceae) flowers that have received a single visit of Eucara macrognatha to the increment of the fruit length is $6.85 \%$ and that of Tetralonia fraterna is $0.90 \%$. This phenomenon was also reported by Vanderborght and Rasmont [27] for Xylocopa bariwal, an efficient $P$. coccineus pollinator.

\section{CONCLUSION}

This study revealed that plants from Small and Red Seed of $P$. vulgaris obtained benefits from pollination by $L$. collaris. 
The comparison of pods and seeds between sets of protected flowers with those of flowers visited only by $L$. collaris underscores the value of this bee in increasing pods and seed yields. The installation of $L$. collaris nest at the proximity of $P$. vulgaris fields is recommended for the increase of pods and seed yields of this valuable crop.

\section{Financial support and sponsorship: Nil.}

Conflict of Interests: There are no conflicts of interest.

\section{REFERENCE}

1. Graham PH, Ranalli P. Common bean (Phaseolus vulgaris L.). Field Crop Research. 1997; 53: 131-146.

2. Ibarra-Perez FJ, Barnhart D, Ehdaie B, Knio KM, W aines JG. Effects of insect tripping on seed yield of common bean. Crop Sciences. 1999; 39: 425-433.

3. Debouck D. Systematics and morphology. In: Common beans: research for crop improvement, Van Schoonhoven, A and Voyset, O (eds), Cali, Colombie. 1991; 55-118.

4. Kingha TMB, Tchuenguem FFN, Ngakou A, Brückner D. Foraging and pollination activities of Xylocopa olivacea (Hymenoptera: Apidae) on Phaseolus vulgaris (Fabaceae) flowers at Dang (Ngaoundere - Cameroon). Journal of Agricultural Extension and Rural Development. 2012; 4: 330 - 339.

5. Douka C, Tchuenguem FFN. Foraging and pollination behavior of Apis mellifera adansonii L. (Hymenoptera, Apidae) on Phaseolus vulgaris (Fabaceae) flowers at Maroua (Cameroon). International Journal of Plant Sciences. 2013; 4(2): 45 - 54.

6. Wells WC, Isom WH, Waines JG. Outcrossing rates of six common bean lines. Crop Sciences. 1988; 28: 177-178.

7. Ibarra-Perez FJ, Ehdaie B, Waines JG. Estimation of outcrossing rate in common bean. Crop Sciences. 1997; 37: 60-65

8. MINADER. Annuaire des Statistiques du Secteur Agricole, Campagnes 2009 \& 2010. Direction des Enquêtes et Statistiques AGRI - STAT CAMEROUN. 2012;17: 123.

9. Letouzey R. Notice de la carte phytogéographique du Cameroun au 1/500000. Inst. Carte. 1985.

10. Kuete M, Melingui A, Mounkam J, Nofiele D. Nouvelle Géographie du Camroun. EDICEF. 1993; 207.

11. Jean-Prost P. Knowing the bees-Leading the hives, Sixth edition, Lavoisier, Paris, France. 1987; 579.

12. Tchuenguem FFN, Messi J, Brückner D, Bouba B, Mbofung G, Hentchoya HJ., Foraging and pollination behavior of the African honey bee (Apis mellifera adansonii) on Callistemon rigidus flowers at Ngaoundéré (Cameroon). Journal of the Cameroon Academy of Sciences. 2004; 4(2): 133-140.

13. Jacob-Renacle. Behavior of domestic and wild forager bees in vergers de pommiers in Belgium. Apidologie. 1989; 20: 271-285.

14. Douka C. Impact de Apis mellifera adansonii, Lipotriches collaris (Hymenoptera: Apoidea) et Musca domestica (Diptera: Muscidae) sur la pollinisation de Phaseolus vulgaris L. (Fabaceae) et de Ricinus communis L. (Euphorbiaceae) à Mayel - Ibbé (Maroua, Cameroun). Thèse de Doctorat/Ph.D., Université de Ngaoundéré. 2015. 159.

15. Tchuenguem FFN, Dounia. Foraging and pollination behavior of Apis mellifera adansonii Latreille (Hymenoptera: Apidae) on Glycine max L. (Fabaceae) flowers at Maroua, Journal of Research in Biology. 2014; 4(1): 1209-1219

16. Kengni BS, Ngakou A, Tchuenguem FFN. Pollination and yield attributes of (cowpea) Vigna unguiculata L. Walp. (Fabaceae) as influenced by the foraging activity of Xylocopa olivacea Fabricius (Hymenoptera: Apidae) and inoculation with Rhizobium in Ngaoundere, Cameroon, International Journal of Agronomy and Agricultural Research. 2015; 6(2): 62-76.
17. Tchuenguem FFN, Djonwangwé D, Messi J, Brückner D Exploitation of Entada africana, Eucalyptus camadulensis, Psidium guajava and Trichillia emetica flowers by Apis mellifera adansonii at Dang (Ngaoundere, Cameroon), Cameroon Journal of Experimental Biology. 2007; 3: 50-60.

18. Tchuenguem FFN, Djonwangwé D, Messi J, Brückner D. Foraging and pollination activities of Apis mellifera adansonii (Hymenoptera: Apidae) at Ngaoundere (Cameroon). Cameroon Journal of Experimental Biology. 2009; 5(1): 1-9.

19. Pando JB, Tchuenguem FFN, Tamesse JL. Pollination and yield responses of pigeon pea (Cajanus cajan L. Mill sp.) to the foraging activity of Chalicodoma cincta cincta (Hymenoptera: Megachilidae) in Yaoundé (Cameroon). Journal of Animal and Plant Sciences. 2011a; 11 (1): 1346 - 1357

20. Pando JB, Tchuenguem FFN, Tamesse JL. Foraging and pollination behaviour of Xylocopa calens (Hymenoptera: Apidae) on Phaseolus coccineus L. (Fabaceae) flowers at Yaoundé (Cameroon). Journal of Entomological Research. 2011b; 41: 185 - 193.

21. McGregor SE. Insect pollination of cultivated crop plants. Agricultural Research Service. United States Department of Agriculture, Agricultural Handbook, Washington. 1976; 496: 411.

22. Dounia, Tchuenguem FFN. Foraging and pollination activity of Apis mellifera adansonii Latreille (Hymenoptera: Apidae) on flowers of Gossypium hirsutum L. (Malvaceae) at Maroua, Cameroon. International Journal of Plant Sciences. 2013; 4(2): 33-44.

23. Dounia, Tchuenguem FFN. Foraging and pollination activity of Macronomia vulpina (Gerstaecker, 1857) (Hymenoptera: Halictidae) on flowers of Gossypium hirsutum L. (Malvaceae) at Maroua, Cameroon. International Journal of Agronomy and Agricultural Research. 2014; 4 (3): 1-10.

24. Tchindébé G, Tchuenguem FFN. Foraging and pollination activity of Apis mellifera adansonii L. (Hymenoptera: Apidae) on flowers Alium cepa L. (Liliaceae) at Maroua, Cameroon. International Journal of Agronomy and Agricultural Research.2014; 5 (2): 139-153.

25. Darwin C. On the agency of bees in the fertilization of papilionaceous flowers, and on the crossing of kidney, Garden Chronic. 1858; 18: 828-829.

26. Azo'o EM, Tchuenguem FFN, Messi J. Influence of the foraging activity of the entomofauna on Okra (Abelmoschus esculentus) seed yield. International Journal of Agriculture \& Biology. 2011; 13 (5): $761-765$.

27. Vanderborght I, Rasmont P. Utilization of the domestic bees (Apis mellifera L.) and the Xylocope (Xylocopa bariwal MAIDL) (Hymenoptera: Apidae) for pollination in cage of Phaseolus coccineus L. Bulletin des recherches agronomiques de Gembloux. 1987; 22(4): 279-284

\section{How to cite this article:}

Douka C, Tamesse JL, Tchuenguem FF. Impact of single visit of Lipotriches collaris Vachal 1903 (Hymenoptera: Halictidae) on Phaseolus vulgaris (Fabaceae) flowers at Maroua (Cameroon). J App Biol Biotech. 2017; 5 (02): 072-076. 